\title{
An ENSO-Forecast Independent Statistical Model for the Prediction of Annual Atlantic Tropical Cyclone Frequency in April
}

\author{
Kenny Xie ${ }^{1}$ and Bin Liu ${ }^{2}$ \\ ${ }^{1}$ Enloe High School, Raleigh, NC, USA \\ ${ }^{2}$ Department of Marine, Earth and Atmospheric Sciences, North Carolina State University, Campus Box 8208, \\ Raleigh, NC 27695, USA
}

Correspondence should be addressed to Bin Liu; bin_liu@ncsu.edu

Received 15 December 2013; Accepted 30 December 2013; Published 18 February 2014

Academic Editor: Lian Xie

Copyright (C) $2014 \mathrm{~K}$. Xie and B. Liu. This is an open access article distributed under the Creative Commons Attribution License, which permits unrestricted use, distribution, and reproduction in any medium, provided the original work is properly cited.

\begin{abstract}
Statistical models for preseason prediction of annual Atlantic tropical cyclone (TC) and hurricane counts generally include El Niño/Southern Oscillation (ENSO) forecasts as a predictor. As a result, the predictions from such models are often contaminated by the errors in ENSO forecasts. In this study, it is found that the latent heat flux (LHF) over Eastern Tropical Pacific (ETP, defined as the region $0^{\circ}-5^{\circ} \mathrm{N}, 115^{\circ}-125^{\circ} \mathrm{W}$ ) in spring is negatively correlated with the annual Atlantic TC and hurricane counts. By using stepwise backward elimination regression, it is further shown that the March value of ETP LHF is a better predictor than the spring or summer ENSO index for Atlantic TC counts. Leave-one-out cross validation indicates that the annual Atlantic TC counts predicted by this ENSO-independent statistical model show a remarkable correlation with the actual TC counts $(R=0.72 ; P$ value $<$ 0.01). For Atlantic hurricanes, the predictions using March ETP LHF and summer (July-September) ENSO indices show only minor differences except in moderate to strong El Niño years. Thus, March ETP LHF is an excellent predictor for seasonal Atlantic TC prediction and a viable alternative to using ENSO index for Atlantic hurricane prediction.
\end{abstract}

\section{Introduction}

Tropical cyclones (TC) are among the most deadly and costly natural disasters on earth [1]. For instance, according to official estimates [2], Hurricane Andrew (1992) struck Miami, Florida, destroyed numerous buildings, and caused more than $\$ 58$ billion in damage. Hurricane Katrina (2005) caused catastrophic inundation, resulting in the loss of over 1600 lives and over $\$ 113$ billion in damages as well as the destruction of coastal wetlands and barrier islands in Louisiana, Mississippi, and elsewhere. Most recently, Hurricane Sandy (2012) caused massive inundation in New Jersey, New York, and nearby coastal areas, resulting in about $\$ 50$ billion in damage and the loss of at least 147 lives [3]. Generally speaking, millions of lives and trillions of dollar worth of properties along the Atlantic and Gulf coasts are at risk to hurricanes each year. Thus, it is important to accurately predict the threat of hurricanes before the start of the hurricane season to empower decision makers for informed disaster prevention and mitigation planning.

However, the accuracy of preseason hurricane prediction has not been satisfactory. "Seasonal hurricane predictions can only forecast so much," proclaimed by a well-established hurricane expert [4]. "Where have all the hurricanes gone?" asked Hennen and Patterson [5] regarding the predicted busy 2013 hurricane season which failed to show up. These questions from the leading media commentators reflected the public's frustration about the inability of the hurricane prediction community to offer reliable and accurate preseason hurricane predictions.

To identify the sources of the error in preseason hurricane prediction, it is necessary to understand what variables are 
used as predictors in preseason hurricane prediction models. Many climatic factors are used in the preseason prediction of the level of Atlantic tropical cyclone activity of the following hurricane season. These factors are typically represented by time series of climatic indices which correlate well with Atlantic hurricane activity. Emanuel [6, 7] described a hurricane as an environmental heat engine driven by sensible and latent heating from the ocean, and therefore it is strongly dependent on sea surface temperature (SST). Goldenberg et al. [8] showed how the Atlantic multidecadal Oscillation (AMO), an index based on North Atlantic SST pattern, is closely linked to the long-term variation of Atlantic hurricane frequency. Wang et al. [9] found that both the Atlantic warm pool (an area of SSTs $>28.5^{\circ} \mathrm{C}$ in tropical Atlantic Ocean) and tropical North Atlantic (TNA; SST anomalies over $6^{\circ}-20^{\circ} \mathrm{N}$, $\left.60^{\circ}-15^{\circ} \mathrm{W}\right)$ SSTs correlate with hurricane activity. Knaff [10] explained that higher tropical Atlantic SSTs result in lower sea level pressure (SLP), which reduces the vertical wind shear and moistens the midtropospheric air. The Atlantic meridional mode (AMM) which is the result of a maximum covariance analysis of SSTs and the zonal and meridional winds over the region $21^{\circ} \mathrm{S}-32^{\circ} \mathrm{N}, 74^{\circ} \mathrm{W}-15^{\circ} \mathrm{E}$ also affects Atlantic hurricane activity [11]. This coupled mode may offer more insight into the environmental conditions affecting hurricane development than SST pattern alone [12]. The AMO can trigger the AMM on decadal time scales. AMM may also result in the linkage between AMO and hurricane activity [13]. The North Atlantic Oscillation (NAO) is a measure of the difference between the Atlantic subtropical high and the Icelandic low. It may also influence hurricane activity and tracks [14].

Although many climatic indices in the Atlantic region are found to correlate well with seasonal Atlantic hurricane activities, none of them are more widely accepted and used for hurricane prediction than the index of El Niño-Southern Oscillation (ENSO). ENSO describes the abnormal warming (cooling) of SST in the Eastern Tropical Pacific (ETP) known as El Niño (La Niña) and the corresponding pressure changes. During El Niño, convection over the ETP is enhanced. This, in turn, leads to westerly upper-tropospheric wind anomalies over the Atlantic. Since the climatological winds in the tropical upper troposphere over the Atlantic are mostly westerly, El Niño-induced upper-tropospheric wind anomalies can increase the vertical wind shear (VWS; [15]). VWS over the main development region (MDR) between $10^{\circ}$ and $20^{\circ} \mathrm{N}$ from Africa to the Americas can significantly reduce hurricane activity [16]. Gray [15] found a significant difference between the number of hurricane days during El Niño (10.9 days per year) and non-El Niño years (23.2 days per year). He also analyzed the influence of the equatorial Quasibiennial Oscillation (QBO) on Atlantic hurricane activity and found strong correlation between them. Bove et al. [17] indicated that the probability of two or more hurricanes making landfall along the U.S. coast is $66 \%$ during La Niña years, $48 \%$ during Niño-neutral years, and only $28 \%$ during El Niño years. Smith et al. [18] further confirmed these differences in Atlantic hurricane activity between ENSO cold and warm years.
Various forms of climatic indices measuring the strength of ENSO have been used as one of the most important predictors in statistical models for the prediction of the seasonal activity of Atlantic hurricanes [14, 15, 19]. However, since the correlation between ENSO and Atlantic hurricane activity does not become significant until July, a major limitation and source of uncertainty in these models are the dependence of the Atlantic hurricane prediction on the prediction of summertime ENSO indices which often contain large uncertainty of their own [20,21]. Xie et al. [22] illustrated the wide spread of Atlantic hurricane forecasts as a function of July-August-September (JAS) ENSO index. Since JAS ENSO index is not available at the time of making preseason hurricane forecasts, predicted values of the index are generally used. Because of the sensitivity of Atlantic hurricane forecasts to ENSO index, error in ENSO forecast inevitably translates into error in the Atlantic hurricane forecasts. Thus, in order to reduce the error of seasonal hurricane prediction, it is necessary to develop a seasonal hurricane prediction model which is independent of the preseason ENSO forecasts. In this study, we will analyze the feasibility of using preseason (spring) air-sea latent heat fluxes in the tropical Pacific Ocean to replace the JAS ENSO index to predict the number of TCs and hurricanes which will develop in the Atlantic each year.

\section{Data and Methods}

2.1. Data. Since the goal is to forecast the number of TCs and hurricanes that form in the Atlantic in each hurricane season, we first need to obtain the annual TC and hurricane counts for the Atlantic basin. The historical TC counts were obtained by manually counting them based on the National Hurricane Center (NHC) HURDAT best track data map available at http://www.nhc.noaa.gov/pastall.shtml, as well as the Re-Analysis project: http://www.aoml.noaa.gov/ $\mathrm{hrd} /$ hurdat/DataByYearandStorm.htm. To train our model, we use past storm counts from the more reliable 1960 to 2011 period. The climatic indices utilized in this study as candidate predictors for the prediction of the TC and hurricane counts for an upcoming hurricane season are almost the same as those used in Keith and Xie [19]. Besides, the QBO index and the ETP LHF are also included as candidate predictors in this study.

The AMM index is the result of a maximum covariance analysis of SSTs and the zonal and meridional winds over the region $21^{\circ} \mathrm{S}-32^{\circ} \mathrm{N}, 74^{\circ} \mathrm{W}-15^{\circ} \mathrm{E}$. AMO is an index based on North Atlantic SSTs. TNA is the anomaly of the average of the monthly SST from $5.5^{\circ} \mathrm{N}$ to $23.5^{\circ} \mathrm{N}$ and $15^{\circ} \mathrm{W}$ to $57.5^{\circ} \mathrm{W}$. TSA is the anomaly of the average of the monthly SST from 0 to $20^{\circ} \mathrm{S}$ and $10^{\circ} \mathrm{E}$ to $30^{\circ} \mathrm{W}$. WHWP is the monthly anomaly of the ocean surface area warmer than $28.5^{\circ} \mathrm{C}$ in the Atlantic and eastern North Pacific. NAO consists of a north-south dipole of anomalies, which has one center located over Greenland and the other center with opposite sign spanning the central latitudes of the North Atlantic between $35^{\circ} \mathrm{N}$ and $40^{\circ} \mathrm{N}$. QBO is calculated from the zonal average of the $30 \mathrm{mb}$ zonal wind 
at the equator as computed from the NCEP/NCAR reanalysis. These climate indices are obtained from http://www.esrl .noaa.gov/psd/data/climateindices/list/.

NINO12 is the SST anomalies in the Niño1+2 region, which is used in this study to represent ENSO impacts. The NINO12 index is obtained from http://www.cpc.ncep .noaa.gov/data/indices/sstoi.indices. NINO12 values for the JAS average during the hurricane season were usually used in building a statistical model. However, the forecast values for NINO12 obtained from global forecast systems (e.g., the National Center for Environmental Prediction's Coupled Forecast System model) are generally used for forecasts of the upcoming hurricane season.

The surface latent heat flux derived from the NCEP/ NCAR reanalysis data is used to compute their correlations with annual Atlantic TC and hurricane counts. The latent heat flux (LHF) values over ETP were extracted from the NCEP/NCAR reanalysis and averaged for each month of the year from 1960 to 2011 to be another candidate predictor.

\subsection{Methods}

2.2.1. Multivariate Linear Regression. Our goal is to estimate the expected number of TCs and hurricanes to form in the Atlantic Ocean, represented by $\lambda$. Forecasts are made for Atlantic TC and hurricane counts, respectively. We use the statistical model of linear regression, which assumes the $\lambda$ to be linearly related to the selected climatic indices. We chose which months to include for the indices following the research of Keith and Xie [19]. Once the months for each index are selected, the monthly averages of the values of the index are calculated each year to create a single monthly time series to represent the index. Before implementing the regression we examine the correlations between the climate indices. All values, except TSA and NINO12, show strong correlation to each other. To alleviate this issue, we perform a stepwise backward elimination regression (SBER) to eliminate less significant and redundant predictors. The linear regression model can be expressed as

$$
\begin{array}{r}
\lambda_{i}=\beta_{0}+\beta_{1} x_{i 1}+\beta_{2} x_{i 2}+\cdots+\beta_{p} x_{i p}+\varepsilon_{i} \\
\text { for } i=1,2, \ldots, n,
\end{array}
$$

where $\beta_{0}$ is the intercept; $\beta_{1}, \beta_{2}$, and $\beta_{3}$, and so forth are the regression coefficients; and $\varepsilon$ is the random error. Using the data from previous years, the coefficients for the predictors are estimated using maximum likelihood methods. With these estimates, we then use the current climate index values to predict the values of $\lambda_{i}$.

The best fitted line minimizes the sum of the squares of deviations from the data points to the line. The least squares constant for each predictor is calculated using the $R$ statistical software.

2.2.2. The SBER Procedure. There are numerous climate indices including those described in Section 2.1 being used as candidate predictors to establish a statistical model for predicting the number of Atlantic TC and hurricanes to form in each season. However, not all of the candidate predictors are independent, and not all of the independent predictors are of equal importance. Inclusion of redundant predictors and too many insignificant predictors can often lead to large model uncertainty [19]. Eight indices were chosen by Keith and Xie [19] for their hurricane prediction model. Similarly, Xie et al. [22] narrowed the number of predictors from 22 to 9 for Atlantic TCs and to 12 for hurricanes by using LASSO [23]. In this study, we will utilize the SBER procedure to rank and select the most significant candidate predictors. The procedure involves starting with all the 9 candidate predictors described in Section 2.1 and progressing to removing each predictor with the least significance that minimally affects the correlation coefficient. This was done repeatedly until the combination of predictors with the highest significance (the lowest $P$ value) was achieved.

2.3. Standardization. Standardization is a process to homogenize the data range for different datasets with large differences in the range of their values. In this study, a standardized time series $A_{s i}$ is obtained from the original time series $A$ according to

$$
A_{s i}=\frac{\left(A_{i}-\bar{A}\right)}{\sigma}, \quad i=1, \ldots, n
$$

where $\sigma$ is the standard deviation of $A$ and $\bar{A}$ is the average of A.

2.4. Leave-One-Out Cross Validation (LOOCV). To validate the predictive skill of a forecast model, it is necessary to make sure that the answer for the prediction is not used to train the model itself in the model development stage. This can be done by removing the year, for which the model is trying to predict, from the training dataset (hence the term leave-oneout) used to develop the prediction model. By removing one year at a time, we can cross validate the forecasts from the regression models not trained by the values of the forecast year.

\section{Results and Discussions}

3.1. Finding a Replacement Predictor for ENSO Index Using SBER. Since sensible and latent heat flux from the ocean is the primary source of energy fueling the development of hurricanes, it is reasonable to explore whether such heat flux in certain regions of the global ocean can be used as a predictor for preseason hurricane prediction. Although lots of climatic variables are commonly used presently in various hurricane prediction models, air-sea sensible or latent heat flux was, surprisingly, not one of them. To study whether airsea heat flux in certain parts of the ocean can be useful predictors, we first created correlation maps that show the areas of significant correlation $(P<0.05)$ between the sensible and 
latent heat flux in a particular month over the global ocean and the annual number of TCs in the North Atlantic Ocean for the period 1960-2011. In this study, only the application of latent heat flux (hereafter referred to as LHF), which is more important than sensible heat flux, is presented to demonstrate the significance of using heat flux as a predictor. The correlation coefficients and the corresponding $P$ values between the annual TC (or hurricane) counts and the LHF at each grid point of the global reanalysis data between 1960 and 2011 are then calculated for each month of the year. A contour map of the correlation coefficients was plotted for each month of the year by averaging the LHF in each month and correlating them with the time series of North Atlantic TC (or hurricane) counts from 1960 to 2011. By inspecting the 12 correlation maps for the 12 months of the year, the most significant regions of correlation are identified. The ETP region $\left[0^{\circ}-5^{\circ} \mathrm{N}, 115^{\circ}-125^{\circ} \mathrm{W}\right]$ turns out to be a region with the most evident and persistent negative correlation, suggesting that an increase in LHF in this region is correlated with a decrease in annual Atlantic TC (or hurricane) count. At first, this seems to be consistent with the effect of $\mathrm{El}$ Niño since the region $\left[0^{\circ}-5^{\circ} \mathrm{N}, 115^{\circ}-125^{\circ} \mathrm{W}\right]$ is within the frequently referenced Niño3.4 region, but it turns out that the correlation between the LHF in Spring (January-March) and the El Niño index (either Niño3.4 or Niñol.2 index) in either Spring or summer (JAS) is insignificant. Furthermore, significant correlation between the LHF in this region and Atlantic annual TC (or hurricane) counts begins to occur as early as January and peaks in March, whereas the correlation between El Niño indices and Atlantic annual TC or hurricane counts is insignificant until midsummer after the start of the Atlantic hurricane season. Thus, the LHF in the ETP region in spring may be a viable candidate predictor for the Atlantic TC or hurricane counts in the following hurricane season.

The monthly averages of the LHF over ETP were then correlated with the number of North Atlantic TCs and hurricanes. It is found that March was the month with the highest correlation, followed by February and January. Therefore, March LHF values in the selected ETP region (referred to as the March LHF index hereafter) have the best potential to be a useful predictor for Atlantic TC and hurricane counts.

To evaluate whether the March LHF index is one of the leading predictors for Atlantic TC counts, the SBER procedure was applied to the March LHF index as well as other candidate predictors described in Section 2.1. Except for the ENSO index which uses JAS average, March values are used for all other predictors so a true prediction can be made in April. Table 1 depicts the top ranked predictors in each step, until the minimum $P$ value is reached. The results clearly demonstrate that the LHF is one of the top 3 predictors for Atlantic TC counts and beats the summer season ENSO index. Therefore, March LHF can be used to replace the JAS ENSO index. It is also worth noting that the QBO index which had been widely used to predict Atlantic TC frequency failed to reach the top 6 predictors in keeping with the finding of Camargo and Sobel [24].

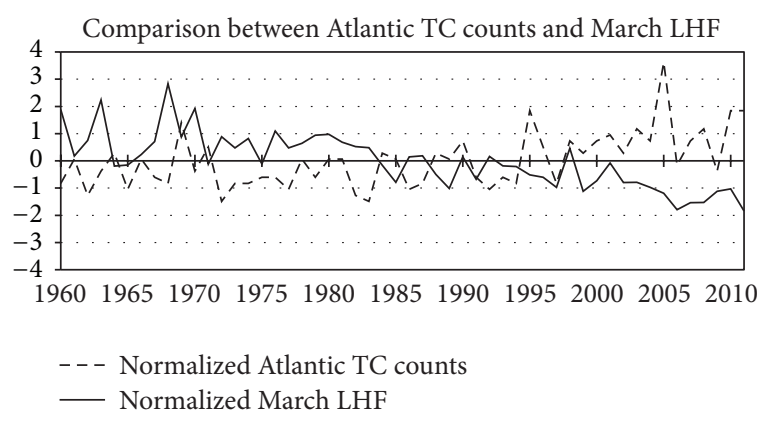

FIGURE 1: Relationship between the standardized March LHF in ETP and the standardized annual counts of Atlantic TCs. A negative correlation between the two is clearly shown.

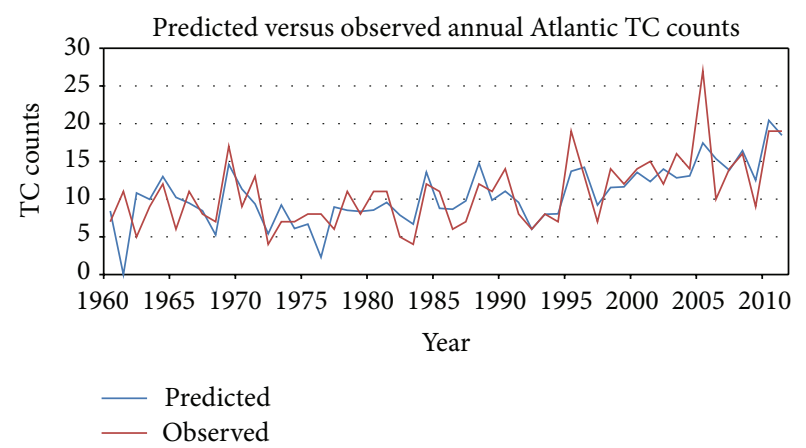

Figure 2: Predicted annual Atlantic TC counts (blue) and corresponding observations (red) from regression model. The two time series show a strong correlation of $R=0.78, P$ value $=3.44 \times 10^{-9}$.

\subsection{Incorporating March LHF in Atlantic TC Prediction Model.} Using the top 4 predictors, TNA, TSA, LHF, and WHWP, we can construct an Atlantic TC prediction model without using the predicted values of ENSO index. Figure 1 shows the relationship between the LHF and Atlantic TC counts from 1960 to 2011. A negative correlation is clearly seen.

A linear regression model for Atlantic annual TC counts based on TNA, TSA, WHWP, and LHF can be established for the period 1960-2011:

$$
\begin{aligned}
\mathrm{TC} \text { count }= & 13.773+5.402 \times \mathrm{TNA}+4.850 \times \mathrm{TSA} \\
& -0.899 \times \mathrm{WHWP}-0.061 \times \mathrm{LHF} .
\end{aligned}
$$

Figure 2 shows the predicted TC counts from the regression model and the observed counts. It has an excellent correlation $\left(R=0.78, P\right.$ value $\left.=3.44 \times 10^{-9}\right)$. If we replace the LHF index with the summer (JAS) ENSO index while keeping TNA, TSA, and WHWP, the regression degrades slightly to $R=0.76$, suggesting an advantage of using LHF instead of the JAS ENSO index even if accurate El Niño forecasts are available.

3.3. Model Validation Using the LOOCV Method. In order to assess the skill of the regression model as presented in (3), the LOOCV method is used. Figure 3 shows the predicted annual Atlantic TC counts as compared to the actual counts. 
TABLE 1: The SBER procedure for selecting predictors. The predictor in bold is selected for elimination in each step. The $R^{2}$ and $P$ value are for the correlation between the regressed and the observed TC counts after a predictor is eliminated. " $\sim$ " presents the list of predictors retained in the previous step.

\begin{tabular}{|c|c|c|}
\hline Predictors & $R^{2}$ & $P$ value \\
\hline All 9 predictors & 0.6322 & $8.67 \times 10^{-7}$ \\
\hline$\sim-\mathbf{A M M}$ & 0.6322 & $2.71 \times 10^{-7}$ \\
\hline$\sim-\mathrm{NINO} 12$ & 0.6164 & $6.21 \times 10^{-7}$ \\
\hline$\sim-\mathrm{AMO}$ & 0.6322 & $2.71 \times 10^{-7}$ \\
\hline$\sim-\mathrm{NAO}$ & 0.6268 & $3.60 \times 10^{-7}$ \\
\hline$\sim-\mathrm{QBO}$ & 0.6321 & $2.71 \times 10^{-7}$ \\
\hline$\sim-\mathrm{TNA}$ & 0.6221 & $4.62 \times 10^{-7}$ \\
\hline$\sim-\mathrm{TSA}$ & 0.6057 & $1.07 \times 10^{-6}$ \\
\hline$\sim-$ WHWP & 0.5983 & $1.54 \times 10^{-6}$ \\
\hline$\sim-\mathrm{LHF}$ & 0.5857 & $2.83 \times 10^{-6}$ \\
\hline \multicolumn{3}{|c|}{ Predictor removed: AMM } \\
\hline$\sim-\mathrm{NINO} 12$ & 0.6162 & $1.87 \times 10^{-7}$ \\
\hline$\sim-$ AMO & 0.6322 & $7.79 \times 10^{-8}$ \\
\hline$\sim-\mathrm{NAO}$ & 0.6267 & $1.06 \times 10^{-7}$ \\
\hline$\sim-\mathrm{QBO}$ & 0.6321 & $7.80 \times 10^{-8}$ \\
\hline$\sim-\mathrm{TNA}$ & 0.5606 & $2.95 \times 10^{-7}$ \\
\hline$\sim-\mathrm{TSA}$ & 0.5427 & $6.56 \times 10^{-6}$ \\
\hline$\sim-$ WHWP & 0.5829 & $1.03 \times 10^{-6}$ \\
\hline$\sim-\mathrm{LHF}$ & 0.5851 & $9.19 \times 10^{-7}$ \\
\hline \multicolumn{3}{|c|}{ Predictor removed: AMO } \\
\hline$\sim-\mathrm{NINO} 12$ & 0.6158 & $5.18 \times 10^{-8}$ \\
\hline$\sim-\mathrm{NAO}$ & 0.6266 & $2.81 \times 10^{-8}$ \\
\hline$\sim-\mathbf{Q B O}$ & 0.6321 & $2.05 \times 10^{-8}$ \\
\hline$\sim-\mathrm{TNA}$ & 0.4348 & $1.62 \times 10^{-4}$ \\
\hline$\sim-\mathrm{TSA}$ & 0.5371 & $2.66 \times 10^{-6}$ \\
\hline$\sim-$ WHWP & 0.5827 & $3.00 \times 10^{-7}$ \\
\hline$\sim-\mathrm{LHF}$ & 0.5802 & $3.39 \times 10^{-7}$ \\
\hline \multicolumn{3}{|c|}{ Predictor removed: QBO } \\
\hline 〜-NINO12 & 0.6152 & $1.30 \times 10^{-8}$ \\
\hline$\sim-\mathrm{NAO}$ & 0.6262 & $6.83 \times 10^{-9}$ \\
\hline$\sim-\mathrm{TNA}$ & 0.4346 & $5.62 \times 10^{-5}$ \\
\hline$\sim-\mathrm{TSA}$ & 0.5353 & $8.20 \times 10^{-7}$ \\
\hline$\sim-$ WHWP & 0.5825 & $7.87 \times 10^{-8}$ \\
\hline$\sim-\mathrm{LHF}$ & 0.5757 & $1.12 \times 10^{-7}$ \\
\hline \multicolumn{3}{|c|}{ Predictor removed: NAO } \\
\hline$\sim-\mathrm{NINO12}$ & 0.6115 & $3.44 \times 10^{-9}$ \\
\hline$\sim-\mathrm{TNA}$ & 0.4121 & $4.05 \times 10^{-5}$ \\
\hline$\sim-\mathrm{TSA}$ & 0.5343 & $2.16 \times 10^{-7}$ \\
\hline$\sim-$ WHWP & 0.5824 & $1.80 \times 10^{-8}$ \\
\hline$\sim-\mathrm{LHF}$ & 0.5606 & $5.74 \times 10^{-8}$ \\
\hline \multicolumn{3}{|c|}{ Predictor removed: NINO12 } \\
\hline$\sim-\mathrm{TNA}$ & 0.3871 & $2.85 \times 10^{-5}$ \\
\hline$\sim-\mathrm{TSA}$ & 0.4950 & $3.05 \times 10^{-7}$ \\
\hline$\sim-$ WHWP & 0.5665 & $8.33 \times 10^{-9}$ \\
\hline$\sim-\mathrm{LHF}$ & 0.5521 & $1.80 \times 10^{-8}$ \\
\hline \multicolumn{3}{|c|}{ Predictor removed: WHWP } \\
\hline
\end{tabular}


TABLE 2: Validation of categorical forecasts. In the rows of FST (forecast) and OBS (observation), “+” stands for above average, “-” for below average, and " $n$ " for years when anomalies of forecast and observation show different signs but the actual difference is within 2 storm counts. In the CMP (comparison) rows, "1" stands for years anomalies of the forecasts and observations show the same sign, "0" stands for different signs with a difference greater than 2 counts.

\begin{tabular}{lcccccccccccccccc}
\hline Yr & 1960 & 1961 & 1962 & 1963 & 1964 & 1965 & 1966 & 1967 & 1968 & 1969 & 1970 & 1971 & 1972 & 1973 \\
\hline FST & - & $n$ & - & - & + & - & $n$ & - & - & + & $n$ & + & - & - \\
OBS & - & $n$ & $n$ & - & + & - & $n$ & - & - & + & $n$ & - & - & - \\
CMP & 1 & 1 & 0 & 1 & 1 & 1 & 1 & 1 & 1 & 1 & 1 & 0 & 1 & 1 \\
\hline Yr & 1974 & 1975 & 1976 & 1977 & 1978 & 1979 & 1980 & 1981 & 1982 & 1983 & 1984 & 1985 & 1986 & 1987 \\
\hline FST & - & - & - & - & $n$ & - & $n$ & $n$ & - & - & + & $n$ & - & - \\
OBS & - & - & - & - & - & - & - & $n$ & - & - & + & - & - & - \\
CMP & 1 & 1 & 1 & 1 & 0 & 1 & 0 & 1 & 1 & 1 & 1 & 0 & 1 & 1 \\
\hline Yr & 1988 & 1989 & 1990 & 1991 & 1992 & 1993 & 1994 & 1995 & 1996 & 1997 & 1998 & 1999 & 2000 & 2001 \\
\hline FST & + & $n$ & + & - & - & - & - & + & + & - & + & + & + \\
OBS & + & $n$ & + & - & - & - & - & + & + & - & - & + & + \\
CMP & 1 & 1 & 1 & 1 & 1 & 1 & 1 & 1 & 1 & 1 & 0 & 1 & + \\
\hline Yr & 2002 & 2003 & 2004 & 2005 & 2006 & 2007 & 2008 & 2009 & 2010 & 2011 & Rate & $\%$ & 1 \\
\hline FST & + & + & + & + & - & + & + & - & + & + & & \\
OBS & + & + & + & + & + & + & + & + & + & + & & \\
CMP & 1 & 1 & 1 & 1 & 0 & 1 & 1 & 0 & 1 & 1 & $44 / 52$ & $85 \%$
\end{tabular}

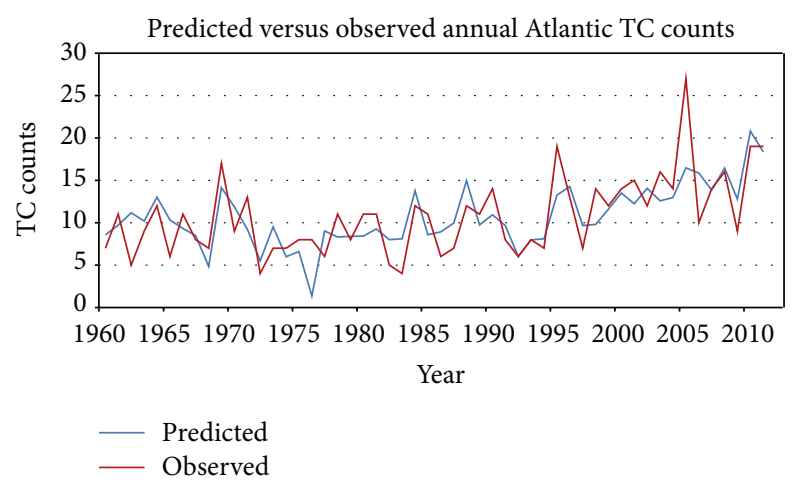

FIgUre 3: Predicted (red) annual Atlantic TC counts using leaveone-out method and the corresponding observations (blue). The two time series show a strong correlation $(R=0.72, P$ value $<0.01)$.

It can be seen that the predicted trends follow closely with those of the observations. Table 2 shows the signs of the predicted and the observed anomalies of Atlantic TC counts where $(+)$ stands for above normal, $(-)$ for below normal, and $(n)$ for near normal (difference within 2 storms of the normal). Over the past 52 years, there were 8 misses and 44 hits, garnering a success rate of $85 \%$. In the recent 25 years since 1986, there were only 3 misses, reflecting an impressive success rate of $88 \%$. In comparison, the success rate in a similar forecast exercise using a more complex "network motif-based machine learning tool" obtained a comparable success rate of $80 \%$ [25]. Thus, with the identification of the spring season LHF as a predictor, even a simple multivariate linear regression model shows the promise of improving preseason Atlantic TC prediction. This promise is further demonstrated by the corresponding scatter plot as shown in

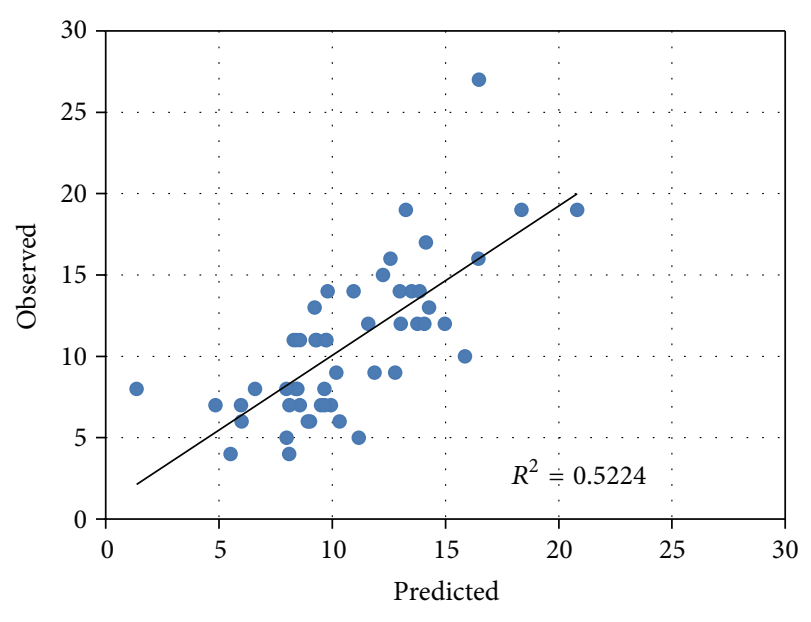

FIGURE 4: Scatter plot of the observed and predicted Atlantic annual TC counts using the LOOCV method $(R=0.72, P$ value $<0.01)$.

Figure 4 . The predicted and the observed annual Atlantic TC counts garnered an impressive positive correlation of $R=$ 0.72 .

3.4. Application to Atlantic Hurricane Prediction. The results from Section 3.3 demonstrate that air-sea latent heat flux in ETP observed in March can be used to predict the annual counts of Atlantic TCs in the following hurricane season (June 1-November 30). This eliminates the need for using the predicted El Niño/La Niña values in such predictions and thus reduces the uncertainty in the preseason prediction of annual counts of Atlantic TCs. Then, the question is whether the same holds true for the more intense hurricanes without counting the tropical storms. To answer this question, we will 
TABle 3: Same as Table 1 but for Atlantic Hurricanes using March NINO12 as a candidate predictor.

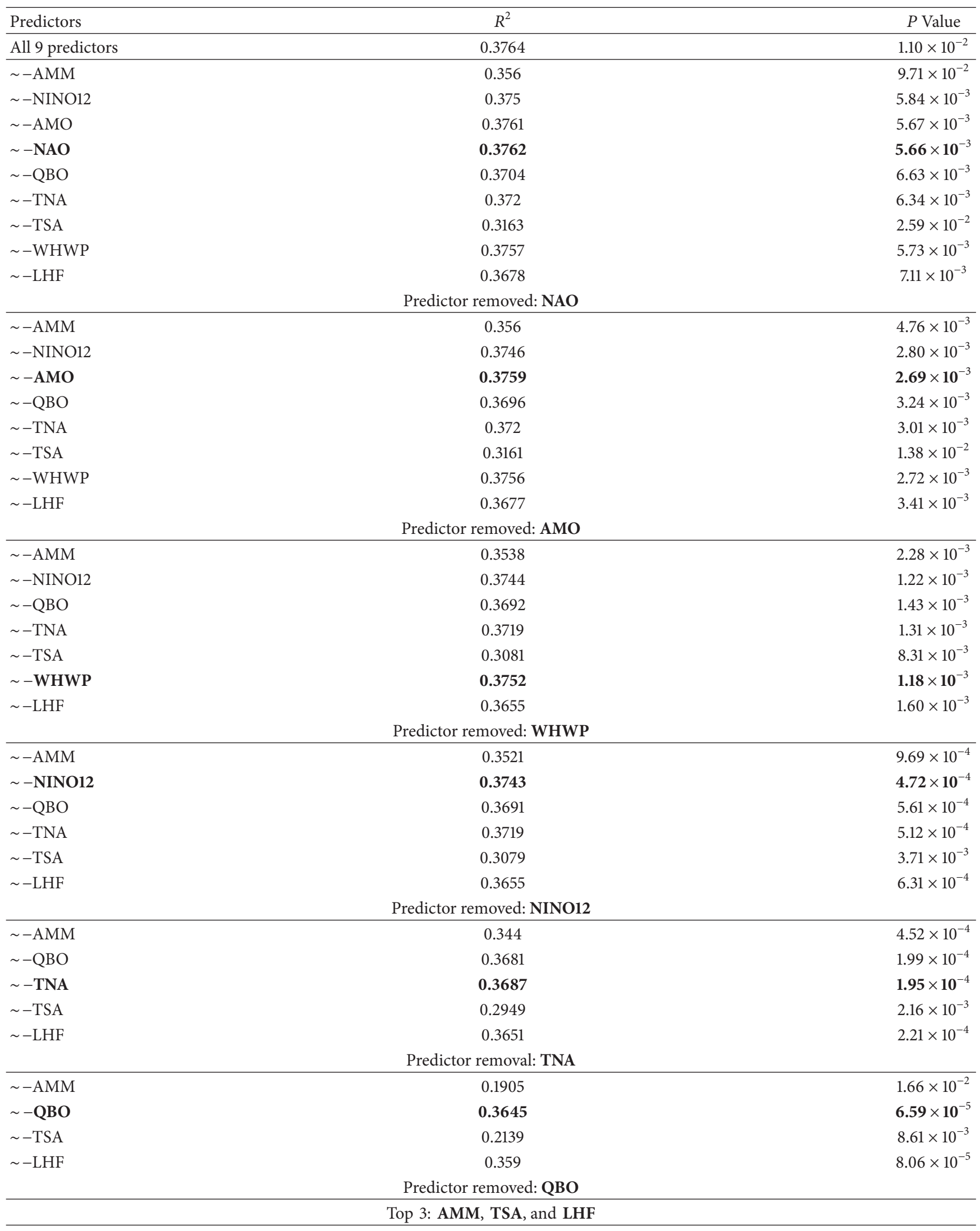


repeat the SBER procedure for hurricanes only. As shown in Table 3, if we include both LHF and the ENSO index in March, the ENSO index was eliminated in the 4th step and failed to enter the top 5 predictors, whereas the LHF index reached top 3.

It is evident that March LHF is preferred over March ENSO index (NINO12) as a predictor for seasonal prediction of Atlantic hurricane counts. This is not surprising since it is well known that the correlation between ENSO and Atlantic hurricane counts does not become significant until midsummer. However, comparing LHF and ENSO indices in the spring season may not be fair since only summer ENSO index values are used in existing hurricane prediction models. Assuming perfect predictions of summer ENSO indices are available, we can then rerank the predictors including both March LHF and JAS ENSO indices. The results of the SBER analysis are shown in Table 4. Not surprisingly, the ENSO index became a top three predictor, whereas LHF is among the top 4, eliminated one step before the ENSO index. This suggests that, if perfect ENSO predictions are available, using ENSO index as a predictor for Atlantic hurricane counts is preferred.

The differences between using March LHF and JAS ENSO indices as predictors are more clearly illustrated by the cross validations of the forecasts using each of them as a predictor. Figure 5 shows the comparison between Atlantic hurricane count predictions using AMM, TSA, and March LHF (blue line) and using AMM, TSA, and JAS NINO12 (green line). The actual regression equations corresponding to these predictions are (4) and (5), respectively. The two predictions are quite similar to their correlation coefficients with the actual counts being 0.2626 and 0.2674 , respectively (Figure 6). A close examination of Figure 5 reveals that the main differences between the two predictions are in years with strong El Niño, notably 1997 (a strong El Niño year) and 2002 (a moderate El Niño year). In both cases, (4) overpredicted by a larger margin than (5). This suggests that, if accurate ENSO forecasts are available, using ENSO index as a predictor is preferred:

$$
\begin{aligned}
\text { hurricane count }= & 6.36461+0.40795 \times \mathrm{AMM} \\
& +3.59514 \times \mathrm{TSA}-0.01018 \times \mathrm{LHF}, \\
\text { hurricane count }= & 5.6204+0.4094 \times \mathrm{AMM}-0.6402 \\
& \times \mathrm{NINO} 12+3.4495 \times \mathrm{TSA} .
\end{aligned}
$$

\section{Conclusions}

In this study, we found that the latent heat flux in ETP within the area of $\left(0^{\circ}-5^{\circ} \mathrm{N}, 115^{\circ}-125^{\circ} \mathrm{W}\right)$ during spring is negatively correlated with the annual count of Atlantic TCs. Through a SBER procedure, the March value of ETP LHF passes the significance test procedure and reaches the list of the top 3 predictors. Surprisingly yet fortunately, both the spring value and the summer value of the ENSO (NINO12) index fail to reach the top 4 predictor list. Therefore, we recommend the use of the March ETP LHF to replace the troublesome

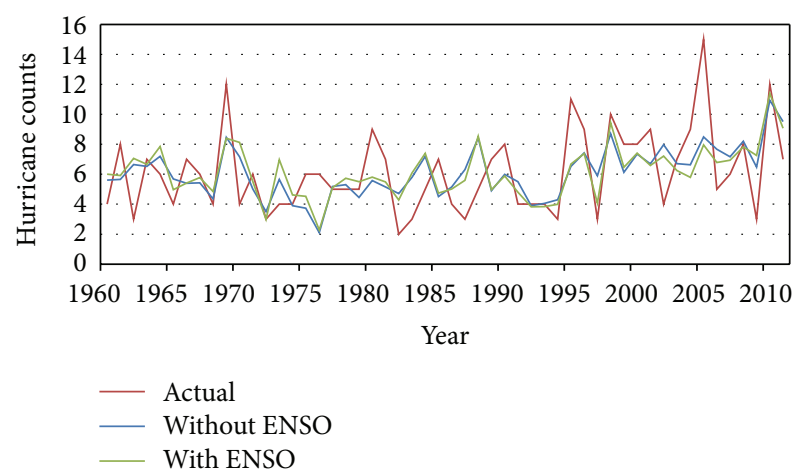

Figure 5: LOOCV of Atlantic hurricane prediction with (green) and without (blue) ENSO as a predictor. Without ENSO, the three predictors are AMM, TSA, and LHF; With ENSO, the three predictors are AMM, TSA, and NINO12.

forecast value of summer ENSO index in the development of statistical models for predicting the seasonal counts of Atlantic TCs. Using the top 4 predictors selected by the SBER procedure, a multivariate linear regression model is developed for preseason (April) prediction of Atlantic TC counts without the use of the ENSO index. The LOOCV method using the top 4 predictors and actual Atlantic TC counts from 1960 to 2011 showed a remarkable correlation between the predicted TC counts and the actual TC counts $(R=0.72 ; P$ value $<0.01)$. The forecast also correctly placed $85 \%$ of the years in the proper category of Atlantic TC activity, namely, above, below, or near (within a difference of two storms between the predicted TC anomaly and the actual anomaly if they are of different signs) normal. This percentage of success rate is substantially higher than that for models using predicted El Niño/La Niña index as a predictor.

The utility of March ETP LHF for predicting annual Atlantic hurricane counts is somewhat different than for the TCs. The results show that, if perfect ENSO predictions are available prior to issuing the hurricane forecast, JAS ENSO index such as NINO12 is a slightly more effective predictor than March ETP LHF during El Niño years. However, during ENSO-neutral or La Niña years, the differences between using March ETP LHF and JAS NINO12 indices are minor. Thus, unless reliable ENSO forecasts are available at the time of issuing the preseason Atlantic hurricane prediction and such forecasts indicate that an El Niño event is to develop during the hurricane season, the use of March LHF remains a better choice than using JAS ENSO forecasts.

The results presented here are limited to the analysis of the value of using the latent heat flux over ETP in March as a potential predictor for preseason prediction of Atlantic annual TC and hurricane counts. Does sensible heat flux over other regions of the global ocean or land affect the variation of Atlantic annual TCs, hurricanes, or major hurricanes? How does latent heat flux affect Atlantic TC and hurricane activity? Does air-sea heat flux affect hurricane tracks? These questions warrant further study in the future. 
TABLE 4: Same as Table 3 but using JAS NINO12 as a predictor.

\begin{tabular}{|c|c|c|}
\hline Predictors & $R^{2}$ & $P$ Value \\
\hline All 9 predictors & 0.4095 & $4.55 \times 10^{-3}$ \\
\hline$\sim-\mathrm{AMM}$ & 0.3949 & $3.34 \times 10^{-3}$ \\
\hline$\sim-\mathrm{NINO} 12$ & 0.375 & $5.84 \times 10^{-3}$ \\
\hline$\sim-\mathrm{AMO}$ & 0.4067 & $2.36 \times 10^{-3}$ \\
\hline$\sim-\mathrm{NAO}$ & 0.4094 & $2.18 \times 10^{-3}$ \\
\hline$\sim-\mathrm{QBO}$ & 0.4006 & $2.83 \times 10^{-3}$ \\
\hline$\sim-\mathrm{TNA}$ & 0.4064 & $2.39 \times 10^{-3}$ \\
\hline$\sim-\mathrm{TSA}$ & 0.369 & $6.87 \times 10^{-3}$ \\
\hline$\sim-$ WHWP & 0.4092 & $2.20 \times 10^{-3}$ \\
\hline$\sim-\mathrm{LHF}$ & 0.4005 & $2.84 \times 10^{-3}$ \\
\hline \multicolumn{3}{|c|}{ Predictor removed: NAO } \\
\hline$\sim-\mathrm{AMM}$ & 0.3945 & $1.54 \times 10^{-3}$ \\
\hline$\sim-\mathrm{NINO} 12$ & 0.3746 & $2.80 \times 10^{-3}$ \\
\hline$\sim-\mathrm{AMO}$ & 0.4067 & $1.05 \times 10^{-3}$ \\
\hline$\sim-\mathrm{QBO}$ & 0.4005 & $1.28 \times 10^{-3}$ \\
\hline$\sim-\mathrm{TNA}$ & 0.4061 & $1.07 \times 10^{-3}$ \\
\hline$\sim-\mathrm{TSA}$ & 0.3689 & $3.30 \times 10^{-3}$ \\
\hline$\sim-$ WHWP & 0.4092 & $9.72 \times 10^{-4}$ \\
\hline$\sim-\mathrm{LHF}$ & 0.4002 & $1.29 \times 10^{-3}$ \\
\hline \multicolumn{3}{|c|}{ Predictor removed: WHWP } \\
\hline$\sim-\mathrm{AMM}$ & 0.3849 & $8.70 \times 10^{-4}$ \\
\hline$\sim-\mathrm{NINO} 12$ & 0.3745 & $1.21 \times 10^{-3}$ \\
\hline$\sim-\mathrm{AMO}$ & 0.4066 & $4.28 \times 10^{-4}$ \\
\hline$\sim-\mathrm{QBO}$ & 0.3997 & $5.38 \times 10^{-4}$ \\
\hline$\sim-\mathrm{TNA}$ & 0.4027 & $4.87 \times 10^{-4}$ \\
\hline$\sim-\mathrm{TSA}$ & 0.3596 & $1.91 \times 10^{-3}$ \\
\hline$\sim-\mathrm{LHF}$ & 0.3991 & $5.50 \times 10^{-4}$ \\
\hline \multicolumn{3}{|c|}{ Predictor removed: AMO } \\
\hline$\sim-\mathrm{AMM}$ & 0.3795 & $3.97 \times 10^{-4}$ \\
\hline$\sim-\mathrm{NINO} 12$ & 0.3743 & $4.72 \times 10^{-4}$ \\
\hline$\sim-\mathrm{QBO}$ & 0.3973 & $2.16 \times 10^{-4}$ \\
\hline$\sim-$ TNA & 0.4017 & $1.85 \times 10^{-4}$ \\
\hline$\sim-\mathrm{TSA}$ & 0.347 & $1.14 \times 10^{-3}$ \\
\hline$\sim-\mathrm{LHF}$ & 0.3921 & $2.59 \times 10^{-4}$ \\
\hline \multicolumn{3}{|c|}{ Predictor removed: TNA } \\
\hline$\sim-\mathrm{AMM}$ & 0.2406 & $1.03 \times 10^{-2}$ \\
\hline$\sim-\mathrm{NINO} 12$ & 0.3687 & $1.95 \times 10^{-4}$ \\
\hline$\sim-\mathbf{Q B O}$ & 0.3946 & $7.76 \times 10^{-5}$ \\
\hline$\sim-\mathrm{TSA}$ & 0.2951 & $2.14 \times 10^{-3}$ \\
\hline$\sim-\mathrm{LHF}$ & 0.3865 & $1.04 \times 10^{-4}$ \\
\hline \multicolumn{3}{|c|}{ Predictor removed: QBO } \\
\hline$\sim-\mathrm{AMM}$ & 0.224 & $6.44 \times 10^{-3}$ \\
\hline$\sim-\mathrm{NINO} 12$ & 0.3645 & $6.59 \times 10^{-5}$ \\
\hline$\sim-\mathrm{TSA}$ & 0.2695 & $1.64 \times 10^{-3}$ \\
\hline$\sim-$ LHF & 0.384 & $3.20 \times 10^{-5}$ \\
\hline \multicolumn{3}{|c|}{ Predictor removed: LHF } \\
\hline
\end{tabular}




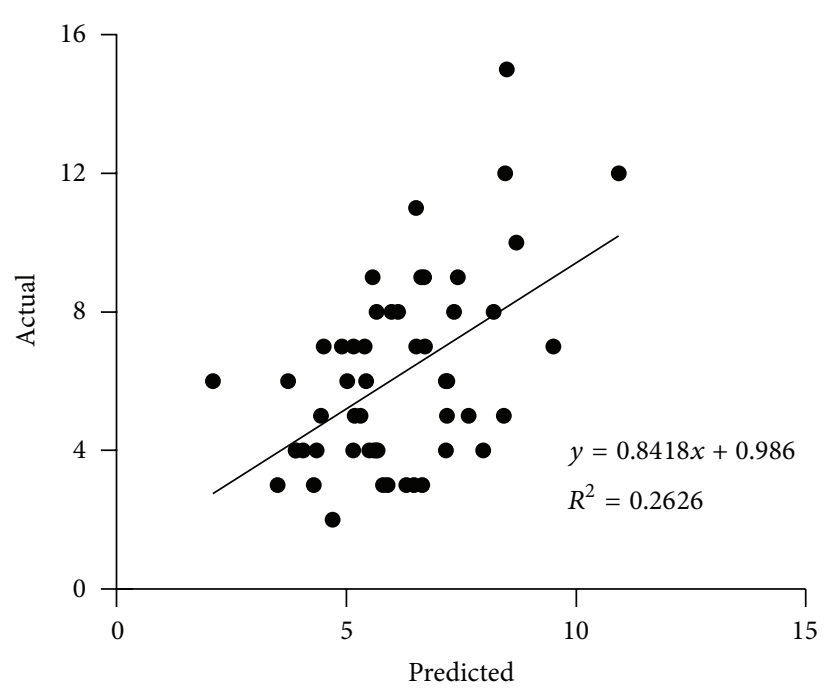

(a)

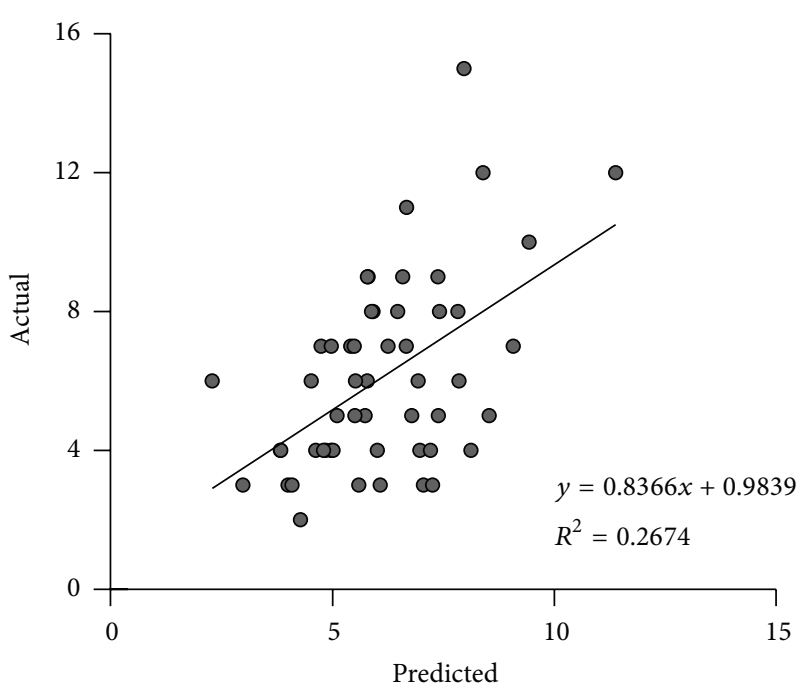

(b)

FIGURE 6: Scatter plot of LOOCV predicted and observed actual counts of Atlantic hurricanes. (a) Using AMM, TSA, and LHF as predictors; and (b) using AMM, TSA, and NINO12 as predictors.

\section{Conflict of Interests}

The authors declare that there is no conflict of interests regarding the publication of this paper.

\section{Acknowledgments}

The main part of this work was conducted when the first author (Kenny Xie) was a summer intern under the supervision of the second author (Bin Liu) at the Coastal Fluid Dynamics Laboratory in NCSU/MEAS. The authors are grateful to Drs. Montserrat Fuentes and Dorit Hamerling for their assistance on the use of statistical tools. This study is supported by the National Oceanic and Atmospheric Administration through subcontract UF-EIES1100D31-NCS and the USA Southeast Coastal Ocean Observing Regional Association (SECOORA) Award IOO.11(03)NCSU.LX.MOD.1.

\section{References}

[1] R. Pielke Jr., J. Gratz, C. Landsea, D. Collins, M. Saunders, and R. Musulin, "Normalized hurricane damage in the United States: 1900-2005," Natural Hazards Review, vol. 9, no. 1, pp. 29-42, 2008.

[2] E. S. Blake, C. W. Landsea, and E. J. Gibney, "The deadliest, costliest, and most intense United States tropical cyclones from 1851 to 2010 (and other frequently requested hurricane facts)," NOAA technical memorandum NWS NHC-6, 2011, http://www.nhc.noaa.gov/pdf/nws-nhc-6.pdf.

[3] E. S. Blake, T. B. Kimberlain, R. J. Berg, J. P. Cangialosi, and J. L. Beven II, Tropical Cyclone Report : Hurricane Sandy, (AL182012), National Hurricane Center, 2013.

[4] I. Adamow, "Seasonal Hurricane Predictions Can Only Forecast So Much," Boston Daily, 2013, http://www.bostonmagazine .com/news/blog/2013/08/09/seasonal-hurricane-predictionscan-only-forecast-so-much/.
[5] D. Hennen and T. Patterson, "Where have all the hurricanes gone?" CNN, 2013, http://www.cnn.com/2013/09/14/us/ hurricane-season-prediction-mystery/.

[6] K. A. Emanuel, "The dependence of hurricane intensity on climate," Nature, vol. 326, no. 6112, pp. 483-485, 1987.

[7] K. A. Emanuel, "The theory of hurricanes," Annual Review of Fluid Mechanics, vol. 23, pp. 179-196, 1991.

[8] S. B. Goldenberg, C. W. Landsea, A. M. Mestas-Nunez, and W. M. Gray, "The recent increase in Atlantic hurricane activity: causes and implications," Science, vol. 293, no. 5529, pp. 474479, 2001.

[9] C. Z. Wang, D. B. Enfield, S. K. Lee, and C. W. Landsea, "Influences of the Atlantic warm pool on Western Hemisphere summer rainfall and Atlantic hurricanes," Journal of Climate, vol. 19, no. 12, pp. 3011-3028, 2006.

[10] J. A. Knaff, "Implications of summertime sea level pressure anomalies in the tropical Atlantic region," Journal of Climate, vol. 10, no. 4, pp. 789-804, 1997.

[11] J. C. H. Chiang and D. J. Vimont, "Analogous Pacific and Atlantic meridional modes of tropical atmosphere-ocean variability," Journal of Climate, vol. 17, no. 21, pp. 4143-4158, 2004.

[12] J. P. Kossin and D. J. Vimont, "A more general framework for understanding Atlantic hurricane variability and trends," Bulletin of the American Meteorological Society, vol. 88, no. 11, pp. 1767-1781, 2007.

[13] D. J. Vimont and J. P. Kossin, “The Atlantic meridional mode and hurricane activity," Geophysical Research Letters, vol. 34, Article ID L07709, 2007.

[14] J. B. Elsner, “Tracking hurricanes," Bulletin of the American Meteorological Society, vol. 84, no. 3, pp. 353-356, 2003.

[15] W. M. Gray, "Atlantic seasonal hurricane frequency-part I: El Nino and $30 \mathrm{mb}$ quasi-biennial oscillation influences," Monthly Weather Review, vol. 112, no. 9, pp. 1649-1668, 1984.

[16] W. M. Gray, "Strong association between West African rainfall and U.S. landfall of intense hurricanes," Science, vol. 249, no. 4974, pp. 1251-1256, 1990. 
[17] M. C. Bove, J. B. Elsner, C. W. Landsea, X. F. Niu, and J. J. O'Brien, "Effect of El Niño on U.S. landfalling hurricanes, revisited," Bulletin of the American Meteorological Society, vol. 79, no. 11, pp. 2477-2482, 1998.

[18] S. R. Smith, J. Brolley, J. J. O’Brien, and C. A. Tartaglione, "ENSO's impact on regional U.S. hurricane activity," Journal of Climate, vol. 20, no. 7, pp. 1404-1414, 2007.

[19] E. Keith and L. Xie, "Predicting Atlantic tropical cyclone seasonal activity in April," Weather and Forecasting, vol. 24, no. 2, pp. 436-455, 2009.

[20] H. Paeth, A. Scholten, P. Friederichs, and A. Hense, "Uncertainties in climate change prediction: El Niño-Southern Oscillation and monsoons," Global and Planetary Change, vol. 60, no. 3-4, pp. 265-288, 2008.

[21] C. W. Landsea and J. A. Knaff, "How much skill was there in forecasting the very strong 1997-98 El Niño?" Bulletin of the American Meteorological Society, vol. 81, no. 9, pp. 2107-2119, 2000.

[22] L. Xie, D. Hammerling, B. Liu, and M. Fuentes, "2013 Atlantic tropical cyclone outlook," 2013, http://cfdl.meas.ncsu .edu/research/TCoutlook_2013.pdf.

[23] R. Tibshirani, "Regression shrinkage and selection via the lasso," Journal of the Royal Statistical Society B, vol. 58, no. 1, pp. 267288, 1996.

[24] S. J. Camargo and A. H. Sobel, "Revisiting the influence of the Quasi-biennial oscillation on tropical cyclone activity," Journal of Climate, vol. 23, no. 21, pp. 5810-5825, 2010.

[25] Z. Chen, W. Hendrix, H. Guan et al., "Discovery of extreme events-related communities in contrasting groups of physical system networks," Data Mining and Knowledge Discovery, vol. 27, no. 2, pp. 225-258, 2013. 

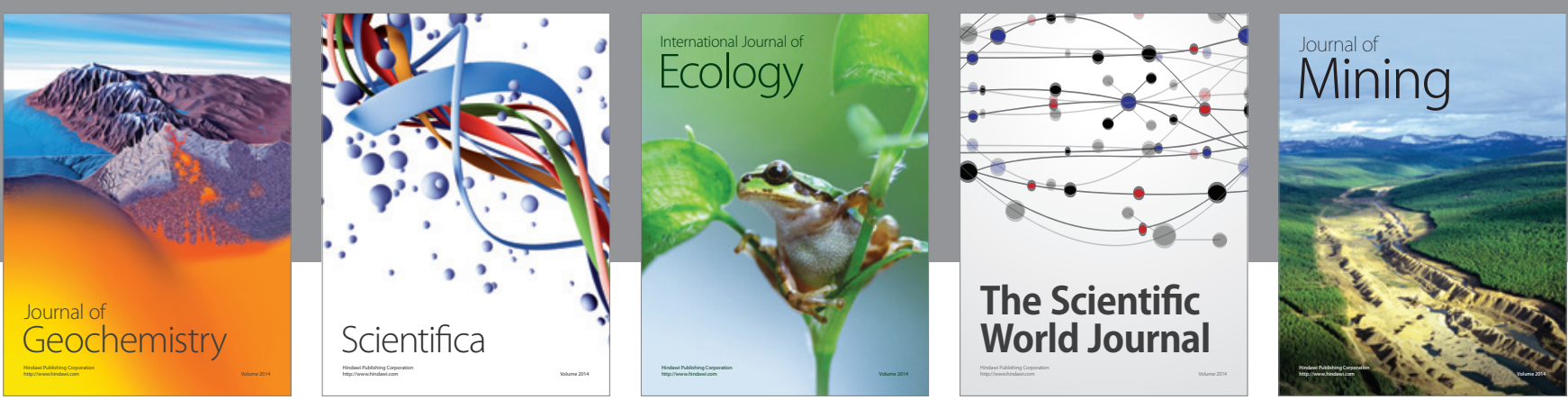

The Scientific World Journal
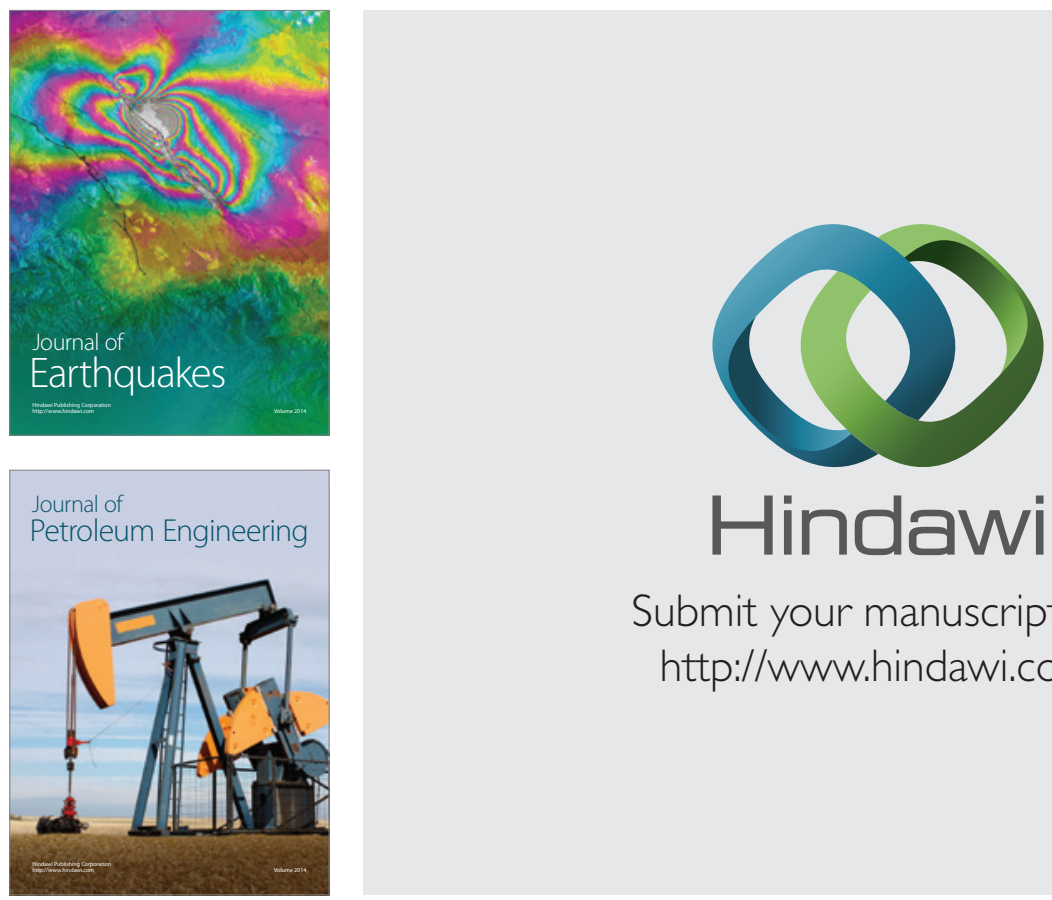

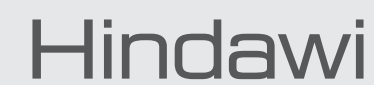

Submit your manuscripts at

http://www.hindawi.com
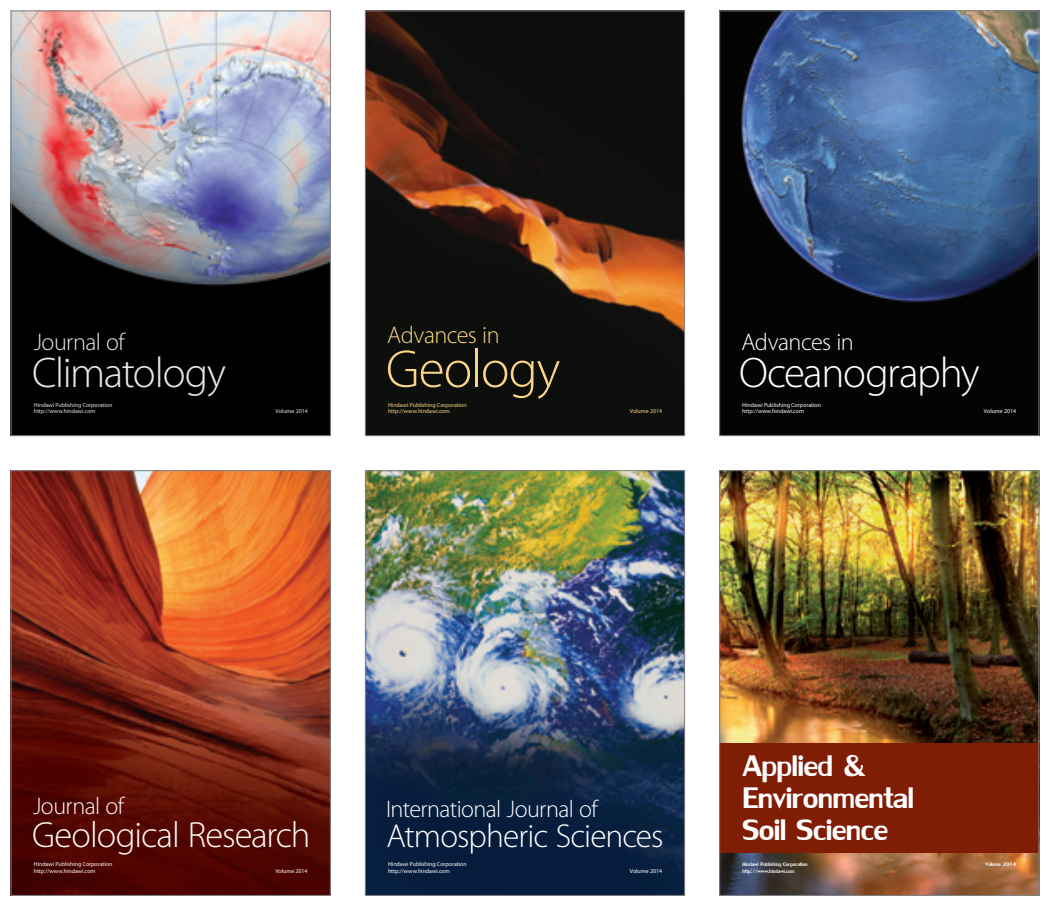
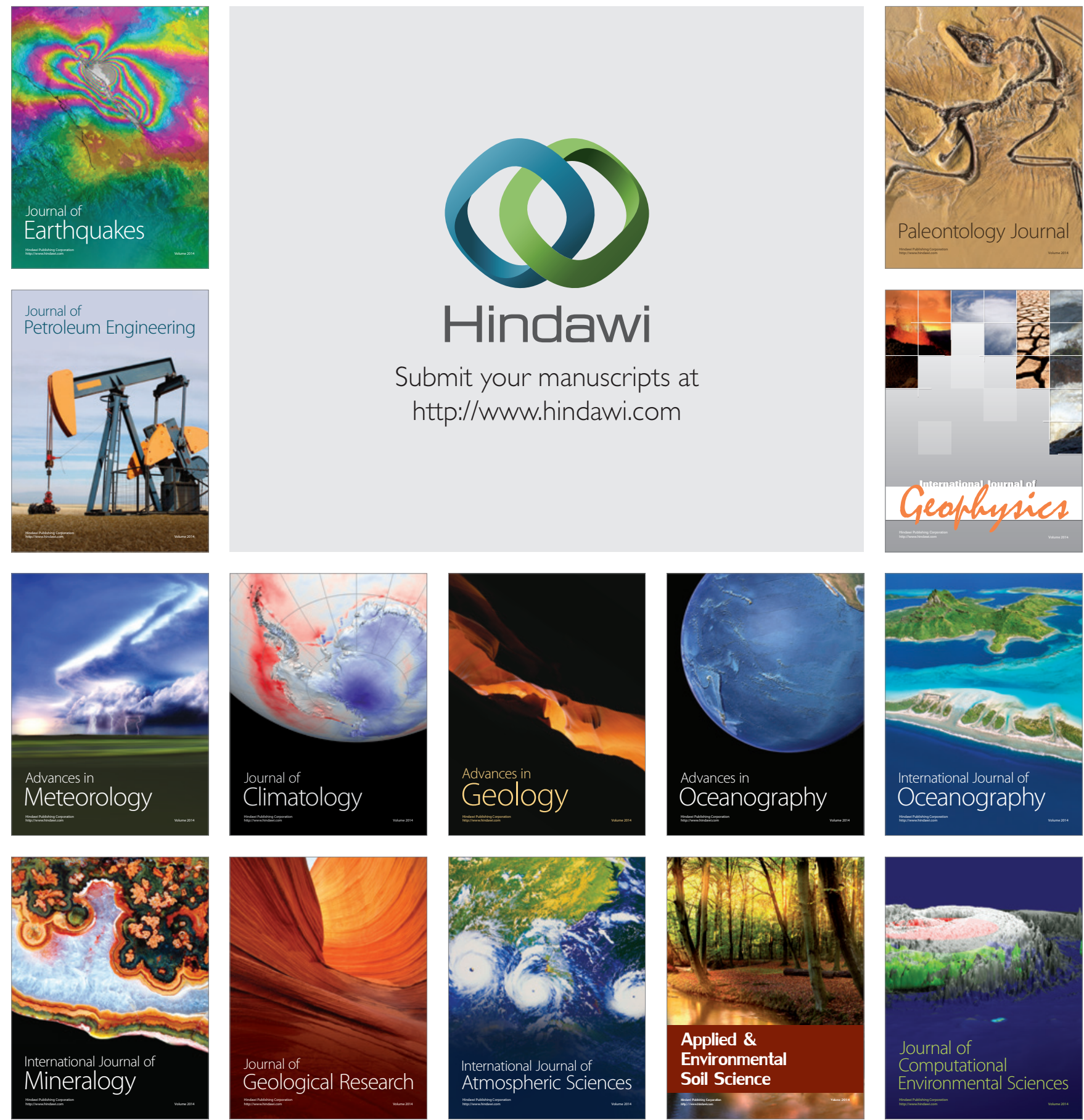